\title{
Chemoresponse of actinosporean spores of Myxobolus cultus to skin mucus of goldfish Carassius auratus
}

\author{
Hiroshi Yokoyama, Kazuo Ogawa, Hisatsugu Wakabayashi \\ Department of Fisheries, Faculty of Agriculture, The University of Tokyo, Yayoi 1-1-1, Bunkyo-ku, Tokyo 113, Japan
}

\begin{abstract}
Chemoresponse of actinosporean spores of Myxobolus cultus to goldfish mucus was studied and determination of the reactants was attempted. Reactivity was counted as the percentage of empty actinosporean spores after mixing with the mucus. The activity of mucus was maintained at $-80^{\circ} \mathrm{C}$, but was mostly lost within $1 \mathrm{~d}$ at $5^{\circ} \mathrm{C}$. Heating at 30 to $80^{\circ} \mathrm{C}$ for 30 min did not affect the activity. While neutral $\mathrm{pH}$ favored the reaction, strong acid and alkali decreased the reaction. Phosphate buffer saline and sodium chloride solutions with molarity $>0.05 \mathrm{M}$ inhibited the reaction. A shrinkage of sporoplasms inside the epispore cavity caused by the high osmotic pressure was observed. Purification of the reactants from goldfish mucus by gel filtration and ultrafiltration revealed that they were low-molecular-weight substances ( $<6000 \mathrm{MW}$ ). Additionally, fish mucus from other fish species (such as common carp Cyprinus carpio, loach Misgurnus anguillicaudatus, rainbow trout Oncorhynchus mykiss, catfish Parasilurus asotus, and Japanese eel Anguilla japonica), as well as mucin from bovine submaxillary gland were similarly active. It is suggested that actinosporean spores recognize fish hosts with low-molecular-weight mucin components in skin mucus, and that the portal of entry is the outer surface of fish.
\end{abstract}

KEY WORDS: Myxosporean - Actinosporean - Myxobolus cultus - Goldf $15 h \cdot$ Carassius auratus $\cdot$ Skin mucus

\section{INTRODUCTION}

Recently, there have been many reports about the transmission of myxosporeans particularly the 2-host life cycle involving vertebrate and invertebrate hosts (Wolf \& Markiw 1984, El-Matbouli \& Hoffmann 1989, Yokoyama et al, 1993a). However, the articles on the portals of entry of myxosporeans to fish are limited only to research on Myxobolus cerebralis (Daniels et al. 1976, Markiw 1989). It has been suggested that $M$. cerebralis penetrated through the skin and/or gills of fish as evidenced by the presence of development stages in the skin, fins, buccal cavity and digestive tract of fish exposed to the infective stage.

We have shown that Myxobolus cultus Yokoyama, Ogawa et Wakabayashi in goldfish Carassius auratus undergoes alternate development as an actinosporean formerly identified as Raabeia sp. in the oligochaete Branchiura sowerbyi (Yokoyama et al. 1991, 1995). In a previous paper (Yokoyama et al. 1993b), it was suggested that the route of entry of this parasite was the body surface of fish as manifested by the presence of sporoplasm released from the spores in contact with the skin mucus of fish, and that chemotaxis was present at the host-finding mechanism of actinosporeans. The response of sporoplasm release in contact with the mucus from goldfish, common carp Cyprinus carpio, and loach Misgurnus anguillicaudatus was observed, but not with the mucus from Japanese eel Anguilla japonica. The above observations raised further questions. Is the reactant a substance (or substances) specific for Cypriniformes? Does the chemotaxis at the host-finding reflect the host-specificity of myxosporeans?

In this paper, we further studied the response of actinosporean spores of Myxobolus cultus with mucus, and tried to determine the reactants.

\section{MATERIALS AND METHODS}

Actinosporean spores of Myxobolus cultus were collected from Branchiura sowerbyi individually placed in $2 \mathrm{ml}$ well plates (Yokoyama et al. 1991). 
Spores released from the oligochaete within 24 h were used in the following studies.

Preparation of mucus from goldfish. Ten healthy goldfish (average body weight $55 \mathrm{~g}$ ) were anaesthetized with di-phenoxyethanol. The body surface of the fish was rinsed with distilled water, and the skin mucus was collected by wiping with a vinyl glove. The mucus was filtered with a gauze to remove fish scales or tissue residues, and then centrifuged at $15000 \times g$ for $15 \mathrm{~min}$. The supernatant was filtered with a $0.22 \mu \mathrm{m}$ membrane filter (Millecs GV, Millipore) and used in the following tests

Assay of the response of Myxobolus cultus to the mucus. A $10 \mu \mathrm{l}$ aliquot of actinosporean spores of $M$. cultus at a concentration of $1 \times 10^{4}$ spores $\mathrm{ml}^{-1}$ and the same amount of mucus was mixed in a $0.3 \mathrm{ml}$ well of a 96-well plate (Corning), and then 5 ul of $10 \%$ neutralized formalin was added to stop the reaction. The reactivity of the mucus to actinosporean spores was quantified by counting the number of empty spores without sporoplasms in 50 spores by phase-contrast microscopy. To determine the optimal mixing time of spores and mucus, reactivity was counted at 1,2,3,5,10 and 15 min after spores were mixed with mucus.

Activity of goldfish mucus. Effects of storage: The mucus was divided into $1 \mathrm{ml}$ aliquots, and kept in a freezer at $-80^{\circ} \mathrm{C}$ or in a refrigerator at $5^{\circ} \mathrm{C}$. The samples that were kept at $5^{\circ} \mathrm{C}$ were divided into 2 groups: one was added to the antibiotic penicillin $G$ potassium (MEIJI) at $1000 \mathrm{IU} \mathrm{ml}^{-1}$ to inhibit bacterial proliferation, while another was not. The activity of mucus was measured on $1,2,3,5,7$ and $14 \mathrm{~d}$. On the last day, inactivated mucus was strongly agitated by pipetting and activity was measured again.

Effects of heating: The mucus samples which were diluted 1:3 with distilled water were heated at a series of temperatures of $30,40,50,60,70$ and $80^{\circ} \mathrm{C}$ for $30 \mathrm{~min}$. After the samples were cooled with running water, their activities were measured.

Effects of $\mathrm{pH}$ : The mucus was diluted 1:2 with $0.01 \mathrm{M}$ phosphate buffer saline (PBS) at different pHs (3 to 11), and activities were measured. PBS without mucus served as a negative control.

Effects of molarity: The mucus was diluted 1:2 with PBS in the range 0.001 to $0.1 \mathrm{M}$ and $1: 10$ with sodium chloride $(\mathrm{NaCl})$ solutions in the range 0.005 to $0.5 \mathrm{M}$. Mucus diluted with distilled water served as a positive control. The activities of the preparations were determined in the same manner.

Purification of the reactant in mucus. To purify the reactant in the crude mucus from goldfish, a gel filtration and an ultrafiltration were performed. A $3 \times 80 \mathrm{~cm}$ Toyopearl HW-65, Superfine the separation range of molecular weight was $7 \times 10^{4}$ to $7 \times 10^{6}$; Tosoh Co. Ltd, Japan) column was used at a flow rate of $20.0 \mathrm{ml} \mathrm{h}^{-1}$ with $0.01 \mathrm{M}$ Tris-HCl buffer ( $\mathrm{pH} 7.2$ ). Samples were collected at a volume of $4.4 \mathrm{ml}$ tube $^{-1}$. Activities to actinosporean spores of Myxobolus cultus and optical absorbances at $280 \mathrm{~nm}$ of the fractions were measured. The fractions with activity were pooled and concentrated by ultrafiltration at a pore size of 13000 or 6000 MW (Mini-Module model NM-3, Asahikasei Co. Ltd, Japan). Activities of the concentrated fractions and the ones passed through the membranes were examined. $0.01 \mathrm{M}$ Tris- $\mathrm{HCl}$ buffer served as a negative control

Activities of other mucus materials. Skin mucus from other fish species such as common carp, loach, rainbow trout, catfish Parasilurus asotus, and Japanese eel were used as mucus materials. In addition, mucin from bovine submaxillary gland (Type I-S M3895, Sigma) were also used. Mucus samples from the above fishes were prepared in the same manner as with the goldfish. Mucin was dissolved in distilled water at $0.1 \%(\mathrm{w} / \mathrm{v})$. Then activities of each material to actinosporean spores of Myxobolus cultus were measured

\section{RESULTS}

\section{Assay of the response of Myxobolus cultus to the mucus}

The response of sporoplasm release was so quick (within $1 \mathrm{~min}$ ) that it was not related to the mixing time of $15 \mathrm{~min}$.

\section{Activity of goldfish mucus}

Effects of storage

Before storage, $76 \%$ of actinosporean spores of Myxobolus cultus reacted to the mucus. The mucus was almost completely inactivated after $1 \mathrm{~d}$ at $5^{\circ} \mathrm{C}$, whereas the activity was maintained at $-80^{\circ} \mathrm{C}$ during the test-period (Fig. 1). Penicillin did not affect the activity. The agitation by pipetting of inert mucus resulted in a considerable recovery in the activity.

\section{Effect of heating}

Heating at 30 to $80^{\circ} \mathrm{C}$ for $30 \mathrm{~min}$ did not affect the activity of the mucus.

\section{Effects of $\mathrm{pH}$}

In the negative controls (at different pHs of PBS without mucus), no response was observed at all pHs tested. Neutral conditions in $\mathrm{pH}$ were favorable in the reaction, and the optimal pH was 7 The activities in strong acid and alkali were comparatively low (Fig. 2). 


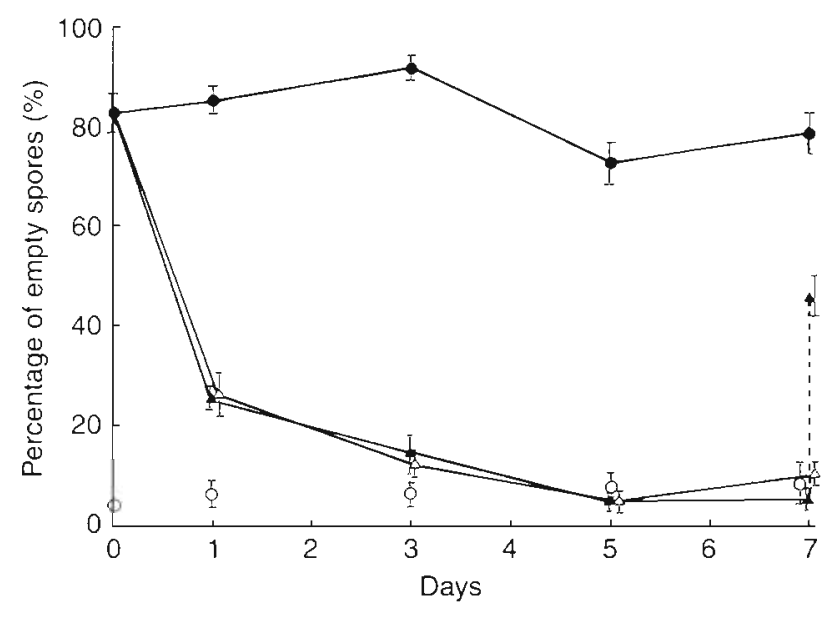

Fig. 1. Myxobolus cultus. Effects of storage of mucus on activity to actinosporean spores. (0) Control; $(\bullet$ mucus stores at $-80^{\circ} \mathrm{C} ;(\Delta)$ mucus stores at $5^{\circ} \mathrm{C}$ (with penicillin); ( $\Delta$ ) mucus stored at $5^{\circ} \mathrm{C}$ (without antibiotics). Dotted line: activation of inert mucus through agitation with pipet. Vertical bars indicate SE $(n=6)$

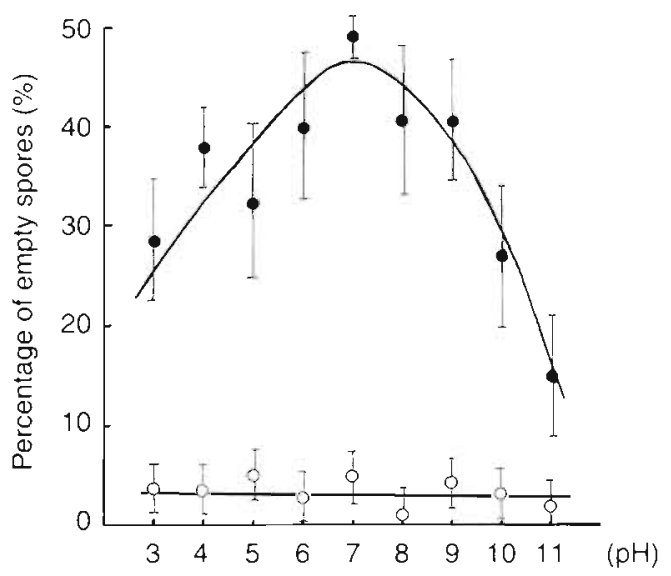

Fig. 2. Myxobolus cultus. Effects of $\mathrm{pH}$ of PBS $(0.01 \mathrm{M})$ diluting mucus on activity to actinosporean spores. $(\bullet, 0)$ PBS with and without mucus, respectively. Vertical bars indicate SE $(n=6)$

\section{Effects of molarity}

Reactions in lower molarities of PBS were very similar to those in distilled water, but molarities $>0.05 \mathrm{M}$ inhibited the reaction. In the same manner, molarities of $\mathrm{NaCl}>0.05 \mathrm{M}$ also prevented the response (Fig. 3). In higher molar solutions, shrinkage of sporoplasms in the epispore cavity of Myxobolus cultus were observed (Fig. 4).

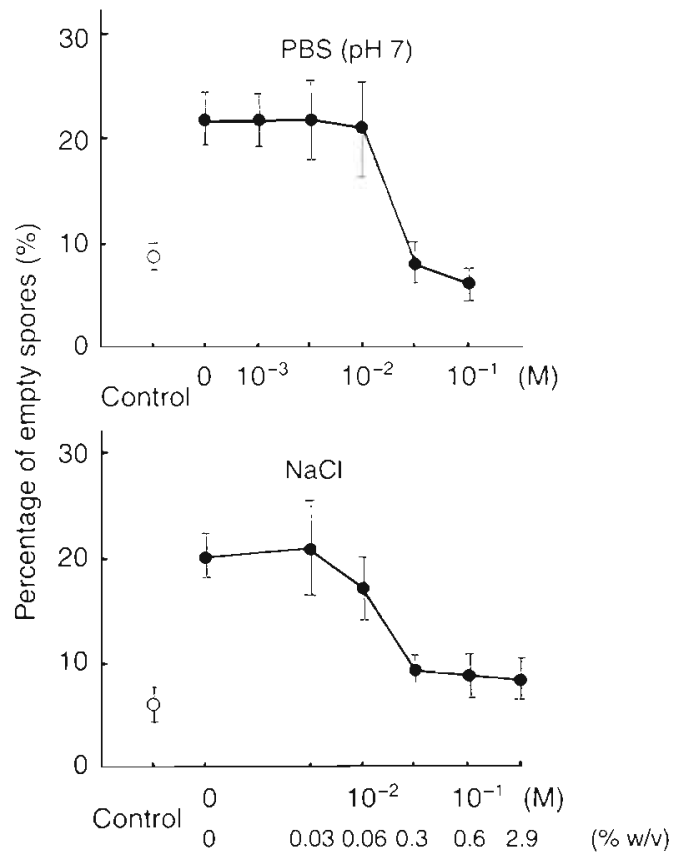

Fig. 3. Myxobolus cultus. Effects of molarity of PBS (pH 7) and $\mathrm{NaCl}$ solution diluting mucus on activity to actinosporean spores. Vertical bars indicate SE $(n=6)$

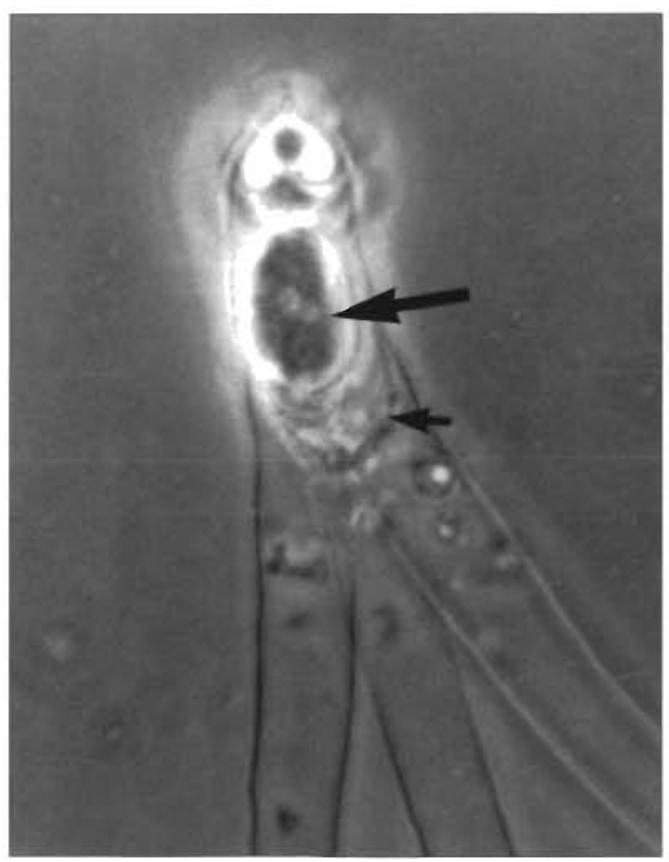

Fig. 4. Myxobolus cultus. Sporoplasm shrinkage of actinosporean spores in $0.5 \% \mathrm{NaCl}$ solution. Large and small arrows show shrinkage sporoplasm and the border of epispore cavity, respectively 


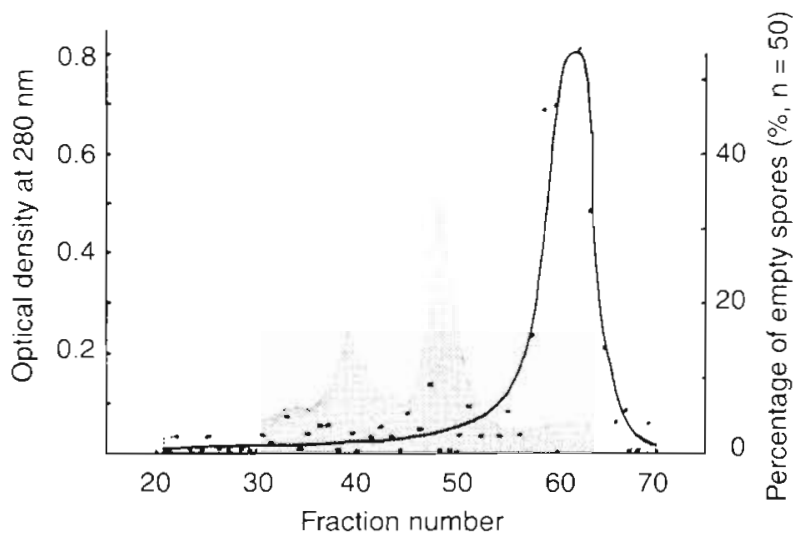

Fig. 5. Myxobolus cultus. Elution profile by gel filtration and the activity to actinosporean spores. Shaded area: relative amount of protein indicated by optical density; line: percentage of empty spores

\section{Purification of the reactant in mucus}

A single peak with the activity in the fraction numbers 59 to 62 was observed in the elution profile of the gel filtration, and the peak was different from the pattern of proteins indicated by absorbance at $280 \mathrm{~nm}$ (Fig. 5). Ultrafiltration of the fractions with activity revealed that the fractions passed through the membranes of 13000 and $6000 \mathrm{MW}$ were active and similar to concentrated fractions (Table 1)

\section{Activity of other mucus materials}

All samples, including the mucus from Japanese eel and the mucin solution, had activity similar to Myxobolus cultus, although a wide variance of the activities was observed (Table 2).

\section{DISCUSSION}

This study indicated that low-molecular-weight component (or components) of mucin induced actinosporean spores of Myxobolus cultus to release the sporoplasm. Determination of the reactant for reactants) requires further study.

Coelenterates, such as hydra, jellyfish, corals and sea anemones, have dischargeable nematocysts morphologically similar to myxosporean polar capsules (Lom 1987), and the extrusion mechanism of nematocysts has been well studied.

Pantin (1942) showed that discharge of nematocysts of Anemonia sulcata required both mechanical contacts and chemical stimuli. Moreover, Thorington \&
Table 1. Activities of mucus fractions separated by ultrafiltrations at pore sizes of 13000 and $6000 \mathrm{MW}(n=50)$. Control: $0.01 \mathrm{M}$ Trus- $\mathrm{HCl}, \mathrm{pH} 7.2$. 'Significantly different from the control (chi-squared analysis)

\begin{tabular}{lc|}
\hline Fraction & Empty spores (\%) \\
\hline Control & 2 \\
Passed through 13000 MW membrane & $31^{\circ}$ \\
Concentrated by 13000 MW membrane & $35^{\circ}$ \\
Passed through $6000 \mathrm{MW}$ membrane & $31^{\circ}$ \\
Concentrated by 6000 MW membrane & $29^{\circ}$ \\
\hline
\end{tabular}

Table 2. Activities of mucus materials from other species in $=$ 50). Control: $0.01 \mathrm{M}$ Tris- $\mathrm{HCl}, \mathrm{pH} 7.2$. 'Significantly different from the control (chi-squared analysis)

\begin{tabular}{lc|}
\hline Source of materials & Empty spores (\%) \\
\hline Control & 5 \\
Common carp Cyprinus carpio & $34^{\circ}$ \\
Loach Misgurnus anguillicaudatus & $15^{\circ}$ \\
Rainbow trout Oncorhynchus mykiss & $48^{\circ}$ \\
Catfish Parasilurus asotus & $20^{\circ}$ \\
Japanese eel Anguilla japonica & $20^{\circ}$ \\
Mucin (bovine submaxillary gland) & $42^{\circ}$ \\
\hline
\end{tabular}

Hessinger (1988) demonstrated that the sea anemone Aiptasia pallida had 2 distinct chemoreceptors: one was specific for free or conjugated $\mathrm{N}$-acetylated sugars, and the other exhibited broad specificity for low-molecular-weight amino compounds.

Watson \& Hessinger (1989) indicated that the sea anemone Haliplanella luciae had a mechanoreceptor with a specific frequency at vibrations of $30,55,65$ and $75 \mathrm{~Hz}$. In the presence of chemical stimulants such as $\mathrm{N}$-acetylated sugars and mucin, however, frequencies shifted to $5,15,30$ and $40 \mathrm{~Hz}$, which corresponded to the movements of swimming prey. They suggested that chemoreceptors tuned mechanoreceptors to frequencies that match the movements of the prey.

It is possible that actinosporeans have a similar discharge mechanism as the nematocysts of coelenterates, although preliminary tests with some lowmolecular-weight substances (some amino acids and $\mathrm{N}$-acetylneuraminic acid) resulted in a negative response to actinosporean spores of Myxobolus cultus. This failure may be explained by the necessity of an adequate physical condition to stimulate mechanoreceptors. Although there is no evidence of a presence of mechanoreceptors on actinosporean spores, the activation of inert mucus through agitation with strong pipetting is suggestive of the involvement of physical condition, possibly viscosity of mucus. During storage of mucus at $5^{\circ} \mathrm{C}$, dissolution of substances decreasing the 
viscosity may have resulted in the inactivation of mucus, and agitating with pipet may have increased the viscosity to recover the activity.

Unexpectedly, the mucus from Japanese eel reacted to actinosporean spores of Myxobolus cultus, although no response was observed in a previous paper (Yokoyama et al. 1993b). What was the difference between them? Was there any inhibitor which had disappeared in the process of preparing mucus solution? Concerning this enigma, a study by Mariscal (1970) on coelenterate may offer some explanation. He studied the anemone fish Amphiprion xanthurus, known for its symbiotic association with sea anemone, and showed that its protection mechanism from the nematocyst discharge was associated with the thick surface coating of the anemone fish, since wiping the surface immediately broke the protection. The nature of the surface covering was unknown, but it is possible that the thick coating inhibits diffusion of chemical sensitizers for nematocyst discharge. In any case, the protection from actinosporean response may be a kind of defense mechanism of Japanese eel against myxosporean infections.

Inhibition of the response in high molarity is thought to be a functional obstruction caused by high osmotic pressure. This result may be applicable to planning measures against myxosporean infections. In a practical sense, keeping fish in $0.3 \% \mathrm{NaCl}(\mathrm{w} / \mathrm{v})$ during the period of actinosporean release may be effective to control myxosporean infection.

In a previous paper (Yokoyama et al. 1993b), we stated that the chemotaxis at the host-finding of actinosporean spores was expected to reflect the specific host-selection of myxosporeans. However, results of the experiments in the present paper indicated that the reactants of Myxobolus cultus were non-specific mucin components, and that Japanese eel possessed an exceptional protection mechanism. These results suggest that this actinosporean may invade many fish species other than Japanese eel. Mechanism on hostspecificity of this myxosporean, therefore, seems to be more related to immunological response after the sporoplasm invades the fish.

\section{LITERATURE CITED}

Daniels SB, Herman, RL, Burke, CN (1976) Fine structure of an unidentified protozoon in the epithelium of rainbow trout exposed to water with Myxosoma cerebralis. J Protozool 23:402-410

El-Matbouli, M, Hoffmann RW (1989) Experimental transmission of two Myxobolus spp. developing biosporogeny via tubificid worms. Parasitol Res 75:461-464

Lom J (1987) Myxosporea: a new look at long-known parasites of fish. Parasitol Today 3:327-332

Mariscal RN (1970) An experimental analysis of the protection of Amphiprion xanthurus Cuvier \& Valenciennes and some other anemone fishes from sea anemones. $J$ exp mar Biol Ecol 4:134-14.9

Markiw ME (1989) Portals of entry for salmonid whirling disease in rainbow trout. Dis aquat Org 6:7-10

Pantin CFA (1942) The excitation of nematocysts. J exp Biol 19:294-310

Thorington GU, Hessinger DA (1988) Control of cnida discharge I. Evidence for two classes of chemoreceptor. Biol Bull 174:163-171

Watson GM, Hessinger DA (1989) Cnidocyte mechanoreceptors are tuned to the movements of swimming prey by chemoreceptors. Science? 243:1589-1591

Wolf K, Markiw ME (1984) Biology contravenes taxonomy in the Myxozoa: new discoveries show alternation of invertebrate and vertebrate hosts. Science 225:1449-1452

Yokoyama H, Ogawa K, Wakabayashi K (1991) A new collection method of actinosporeans - probable infective stage of myxosporeans to fishes - from tubificids and experimental infection of goldfish with the actinosporean Raabeia sp. Fish Pathol 26:133-138

Yokoyama H, Ogawa K, Wakabayashi K (1993a) Involvement of Branchiura sowerbyi (Oligochaeta: Annelida) in the transmission of Hoferellus carassii (Myxosporea: Myxozoa), the causative agent of kidney enlargement disease (KED) of goldfish Carassius auratus. Fish Pathol 28:135-139

Yokoyama H, Ogawa K, Wakabayashi K (1993b) Some biological characteristics of actinosporeans from the oligochaete Branchura sowerbyl. Dis aquat Org 17:223-228

Yokoyama H, Ogawa K, Wakabayashi K (1995) Myxobolus cultus n. sp. (Myxosporea: Myxobolidae) in the goldfish Carassius auratus transformed from the actinosporean stage in the oligochaete Branchiura sowerbyi. J Parasitol (in press)

Manuscript first received: November 9, 1993

Revised version accepted: July 1, 1994 